Gerión. Revista de Historia Antigua

ISSN: 0213-0181

http://dx.doi.org/10.5209/GERI.56953

\title{
La religión como criterio de identidad en la Grecia clásica ${ }^{1}$
}

\author{
$\mathrm{M}^{\mathrm{a}}$ Cruz Cardete del Olmo²
}

Recibido: 12 de diciembre de 2016 / Aceptado: 12 de marzo de 2017

Resumen. Aunque existe una inmensa variabilidad en el conjunto de rasgos empleados por cada pueblo para construir su identidad, lo cierto es que la lengua y la religión son dos de los más repetidos y, por ello, se les suele considerar más importantes para la autodefinición de grupo y menos proclives al cambio que otros, especialmente en el mundo griego antiguo. Este artículo se centra en analizar la relevancia de la religión como criterio a la hora de configurar las identidades griegas antiguas, mostrando en tres niveles (panhelénico, subhelénico y cívico) que la religión no es un criterio homogéneo de helenicidad. A veces separa a griegos, otras veces los une; a veces se encuentra en el centro del debate, otras, en la periferia. Así pues, su importancia e incidencia depende de los contextos históricos y sus vaivenes. Palabras clave: identidad; religión; Grecia antigua; panhelénico; subhelénico; cívico.

\section{[en] Religion as an Identity Criterion in Ancient Greece}

\begin{abstract}
There is a huge variability in the set of features used by every people to build its identity. However, language and religion are two of the most repeated aspects and, therefore, they are usually considered more important for the self-definition of group and less likely to change than others, especially in the ancient Greek world. This article focuses on analyzing the importance of religion as a criterion of identity in classical Greece and shows at various levels (Panhellenic, sub-Hellenic and civic) that religion is not a homogeneous criterion of Greekness. Sometimes, religion divides Greeks; other times it joins them; sometimes religion is in the core of the problem; other times, however, it is on the periphery. So, religion has not a natural relevance, but its importance and incidence vary depending on the historical context.
\end{abstract}

Keywords: Identity; Religion; Ancient Greece; Panhellenic; Sub-Hellenic; Civic.

Sumario. 1. Construyendo identidad en la Grecia Antigua: los Griegos y los Otros. 2. Religión e identidad en la Grecia Antigua. 2.1. El nivel panhelénico: ¿religión griega o religiones griegas? 2.2. El nivel subhelénico: dorios y jonios, entre el enfrentamiento y la reconciliación. 2.3. El nivel cívico: la religión como autodefinición y oposición. 3. Conclusión. 4. Referencias bibliográficas.

Cómo citar: Cardete del Olmo, $\mathrm{M}^{\mathrm{a}} \mathrm{C}$. (2017) La religión como criterio de identidad en la Grecia clásica, en Gerión 35/1, 17-38.

\footnotetext{
1 Este trabajo ha sido realizado dentro del proyecto del MINECO "La construcción socio-cultural del conflicto: procesos y dinámicas de interacción y enfrentamiento en la Grecia arcaica y clásica" (HAR2015-65456-P), del que soy IP.

2 Universidad Complutense de Madrid

E-mail: mcardete@ghis.ucm.es
} 


\section{Construyendo identidad en la Grecia Antigua: los Griegos y los Otros}

Los grupos sociales no son compactos y los griegos antiguos no fueron ninguna excepción. De hecho, cuanto más compleja es una sociedad, más diferencias se encuentran en su seno y más identidades diversas coexisten (sin tener por ello, necesariamente, que excluirse), a modo de diagramas de Venn, que crean realidades nuevas en sus áreas de intersección sin que por ello las zonas de no contacto desaparezcan. ${ }^{3}$

Para que exista, el grupo debe de definirse, diferenciándose de otros grupos que lo rodean, y para ello necesita rasgos particulares, elegidos por ellos mismos y por lo tanto variables, que les categoricen y diferencien de quienes no los poseen o no los perciben de la misma manera. Dichos rasgos no son fijos y, por tanto, no responden a reglas fijas, puesto que deben adaptarse a las necesidades sociales, que cambian con facilidad. No obstante, desde el poder se emplean como escudo sólido y legitiman su fuerza y su aparente inmutabilidad en una supuesta antigüedad que los hace incuestionables y probadamente positivos para el grupo. Dentro de esos rasgos, que son miríada (tradiciones, costumbres, rasgos estilísticos y físicos, formas de organización familiar y/o social, sistemas económicos, historia compartida, imágenes, formas de preparación de los alimentos o la misma naturaleza de estos, textiles, tatuajes y un largo etcétera), destacan dos que los investigadores suelen priorizar sobre todos los demás: la lengua y la religión. Ambos constituyen el núcleo duro de los llamados criterios de identidad y en el imaginario colectivo son los menos proclives al cambio y los que más unen a los miembros de un grupo entre sí (y los separan del resto). Sin embargo, la antropología, la psicología o la historia han demostrado una y otra vez que, aun siendo criterios importantes a la hora de conformar un grupo, ni la religión ni la lengua son imprescindibles ni absolutos y que su aparente impermeabilidad a los cambios sociales es solo una pantalla ideológica que esconde el poder de la lengua $^{4}$ y la religión para conformar una ideología y sostener un statu quo.

En el caso griego, antes del uso generalizado del concepto negativo de bárbaro, que se lleva a cabo durante y a partir de las Guerras Médicas, se emplearon otros, como, por ejemplo, barbarophonos ${ }^{5}$ de carácter precisamente lingüístico. El término designaba a aquel que no hablaba griego o que lo hablaba defectuosamente.

\footnotetext{
A este respecto BRUBAKER $(2004,10)$ ha criticado duramente lo que él califica de "grupismo", es decir, la tendencia desarrollada por algunos miembros (sobre todo los dirigentes) de grupos identitarios de diverso tipo a presentar sus características como propias del grupo en su conjunto, cercenando las diferencias internas y dando a entender que sus decisiones son las de todo el grupo y que cualquiera de sus actuaciones está respaldada por el grupo en su totalidad. Es una estrategia de poder de probada eficacia, pero los investigadores no deberíamos continuarla, sino analizarla.

4 La lengua no es siempre un elemento básico para la conformación de una identidad de grupo (CRIEELAND 2009, 72; Derks - Roymans 2009, 2; Hall 1995, 85; 1997, 170-181; 1998, 266; 2002, 115-117, y 2003, 31; Jones - Graves-Brown 1996, 7; Meskell 2007, 25) y, de hecho, en ocasiones ocurre que un mismo grupo incluye lenguas diversas o que una misma lengua es considerada criterio identitario por parte de grupos distintos (KONSTAN 2001, 31; LuCY 2005, 92).

5 Se encuentra ya en Homero en referencia a los carios (Il. 2.867), aunque se ha llegado a dudar si no se trataría de una interpolación posterior, ya que no vuelve a aparecer hasta mucho después (Hall 2002, 112). En la Odisea Homero utiliza términos similares como agriophonos, empleado para definir a los sinties de Lemnos (8.294), u allothroos, que designa al extranjero lejano que habla una lengua distinta (1.183-184, 3.301-302, 14.43-44 y 15.453), aunque no les imprime tanto un carácter negativo como descriptivo. Las connotaciones peyorativas de la lengua bárbara sí se perciben, en cambio, con claridad en Los Persas de Esquilo (por ejemplo, en el verso 635 , cuando el coro se dirige a Jerjes y emplea la expresión " $\beta \alpha \dot{\alpha} \rho \beta \alpha \rho$ ' $\alpha \sigma \alpha \varphi \eta v \eta ̃$ ” para referirse a la lengua persa [HALL 1989, 75-79]).
} 
Aunque no es un término abiertamente despectivo ni tampoco refleja ninguna esencia insalvable, sí es cierto que contiene un cierto matiz peyorativo en cuanto que no hablar griego, o hablarlo mal, es peor que hacerlo correctamente, pero en todo caso es una diferencia sutil, enmarcada en el ámbito lingüístico y no extrapolable, entre otras cosas porque tampoco había un solo idioma griego ni una sola manera de hablarlo, sino un amplio abanico dialectal de lo más diverso. ${ }^{6}$

Con las Guerras Médicas, en cambio, asistimos al desarrollo de una concepción de la helenicidad que trata de ser perfilada, con límites menos variables que antaño y enmarcada en un profundo enfrentamiento entre, por un lado, algunas poleis griegas $^{7}$ (que tienden a representarse como los "verdaderos griegos", especialmente en el caso de Atenas) ${ }^{8}$ y, por otro, el Imperio persa, que a su vez contó bien con el apoyo (Tebas es quizá el caso más reconocido), ${ }^{9}$ bien con la neutralidad (los argivos emplearon incluso el recurso genealógico para defender su no alienación con Atenas y Esparta frente a Persia), ${ }^{10}$ de variados estados a los que, en principio, las fuentes no califican como otra cosa que griegos. Es en este contexto en el que surge la ya famosa definición herodotea de lo que constituía el ethnos griego:

De hecho, hay muchas y poderosas razones que nos [a los atenienses] impiden hacerlo [aliarse con los persas] aunque quisiéramos. La primera y principal la constituye el incendio y la destrucción de las imágenes y los templos de los dioses, que exigen de nosotros una implacable venganza, en vez de pactar con el autor de tales sacrilegios; por otro lado, está el mundo griego, con su identidad racial y lingüística, con su comunidad de santuarios y de sacrificios a los dioses

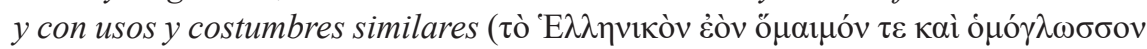

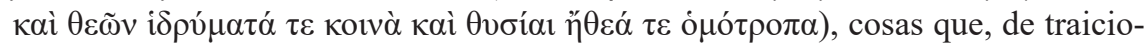
narlas, supondrían un baldón para los atenienses. Sabed, por lo tanto -si es que no lo sabíais ya de antemano-, que mientras quede vivo un solo ateniense jamás pactaremos con Jerjes. ${ }^{11}$

6 Hay que tener en cuenta que no contamos con referencias claras a la existencia de una lengua griega hasta Heródoto (2.154.2: “E $\left.\mathrm{\lambda} \lambda \alpha \dot{\delta} \alpha \alpha \gamma \lambda \tilde{\omega} \sigma \sigma \alpha v^{\prime}\right)$ y que no es nada descartable que fuese más fácil para un hablante del dialecto jonio entenderse con, por ejemplo, un libio con el que tuviera contacto asiduo que con un dorio, puesto que, como defiende Hall (2003, 31, y 2002, 115-117), la mutua inteligibilidad tiene más que ver con la asiduidad del contacto que con correspondencias estructurales entre lenguas o, incluso, entre dialectos.

7 Los principales integrantes de lo que se ha denominado historiográfica y muy significativamente la "Liga Helénica" (a pesar de tener poco de liga y no ser ni más ni menos helénica que muchas otras asociaciones políticas entre poleis) fueron Atenas, Esparta, Corinto, Mégara, Egina, Platea, Calcis y Eretria.

8 Cardete 2011; Hall 1989.

9 Th. 3.62. En el discurso de Tucídides se aprecia que la relación que mantienen plateos y atenienses les parece mucho más reprobable a los tebanos que el hecho de que ellos apoyaran a los persas (mientras que los plateos lucharon dentro de la Liga Helénica), dejando claro que el criterio identitario no es más importante que el político a la hora de forjar alianzas y verse, después, reconvenido por ello. Como siempre, son los intereses contextuales los que deciden con quién aliarse y con qué argumentos justificarlo.

10 Hdt. 7.148-152.

11 Hdt. 8.144. Tanto esta como el resto de citas literales traducidas que aparecen en este artículo proceden en su totalidad de las traducciones de la editorial Gredos. La cursiva es propia. 
No obstante la aparente claridad de la definición herodotea ${ }^{12}$ y de todas las que como ella, en algún momento de la historia, intentan separar nítidamente a unos grupos humanos de otros, los rasgos identitarios no funcionan siempre como un pegamento, tal y como podría pensarse, sino que también pueden hacerlo como un disolvente pues, como ha defendido Bauman, ${ }^{13}$ las identidades responden más a la acción que a la categorización y, por tanto, son más un verbo que actúa que un nombre que designa.

Por tanto, en ocasiones dan cobertura y alientan las semejanzas de unos frente a las diferencias que se advierten con otros, dando lugar a un grupo capaz de ocultar las propias divergencias internas, aunque sea superficialmente y durante poco tiempo, como ocurre precisamente durante el período de las Guerras Médicas en Grecia. Pero otras veces las diferencias internas son tan fuertes y el grupo tan laxo que aquellas acaban corroyéndolo desde dentro, de modo que el grupo, incapaz de gestionar las diferencias que niega que existan, acaba sucumbiendo a ellas y fraccionándose en grupos distintos que emplearán una estrategia de constitución y mantenimiento muy similar: elegir unos rasgos distintivos y enfrentarse a quienes consideran que no los tienen en la misma medida. Así podemos verlo en Tucídides, para quien los verdaderos bárbaros se mostraban en la oposición dorios-jonios que exacerba la Guerra del Peloponeso, ${ }^{14}$ de ahí que el historiador ateniense declare sin ambages que en los tiempos de Homero "los griegos, según creo, todavía no se distinguían con un solo nombre que fuera el contrario (al de los bárbaros)" ${ }^{15}$ y no vea motivos para que eso cambie, puesto que "en muchos otros aspectos, asimismo, se podría demostrar que el mundo griego antiguo vivía de modo semejante al mundo bárbaro de hoy" ${ }^{16}$ Si bien Tucídides da pie a pensar que los bárbaros actuales son inferiores en desarrollo a los griegos, puesto que los compara con helenos antiguos, no hay razón ninguna para aducir, según sus palabras, que bárbaros y griegos se diferencien en esencia, como sí da a entender Heródoto con su categorización.

Teniendo en cuenta lo anterior podemos afirmar que, en general, la necesidad de definirse, de acuñar una identidad y sentirse representados por unos símbolos comunes, vino marcada en la Grecia antigua no tanto por la inclusión de quienes eran griegos en un mismo grupo (la misma definición de griego, cambiante, hace muy difícil saber quiénes y para quiénes lo eran en cada momento),${ }^{17} \mathrm{ni}$ por la actuación consensuada de ese grupo, sino más bien por la necesidad de aquellos que, en determinados momentos, hicieron suya la categoría "helenos" de diferenciarse de quienes consideraban que no pertenecían a ella.

Por lo tanto, continuar defendiendo la existencia de un Nosotros griego compacto es, cuando menos, difícil. El propio Aristóteles se lamenta por ello en un lenguaje abiertamente identitario:

12 Es importante insistir en que la diferencia entre griegos y bárbaros es evidente sólo en apariencia. De hecho, el propio Heródoto fue acusado por Plutarco de filo-bárbaro (Mor. 857a), ya que su posicionamiento respecto a los Otros no puede juzgarse solo por un fragmento de su obra y, en general, dista mucho de ser homogéneo, mostrando admiración por costumbres extranjeras en multitud de ocasiones.

BAUMAN 1996, 19.

Th. 5.9.1, 6.77.1 y 82.2, 7.5.4.

Th. 1.3.3-4.

Th. 1.6.5.

Un ejemplo lo tenemos en el pueblo epirota de los tesprotos, que según Heródoto (2.56) formaba parte de Grecia y según Tucídides (2.80.5) era bárbaro. 


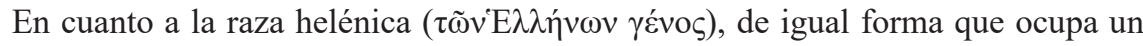
lugar intermedio, así participa de las características de ambos grupos [habitantes de Asia y de Europa], pues es a la vez valiente e inteligente. Por ello vive libre y es la mejor gobernada y la más capacitada para gobernar a todos si alcanzara la unidad política. La misma diversidad se encuentra también entre los pueblos griegos

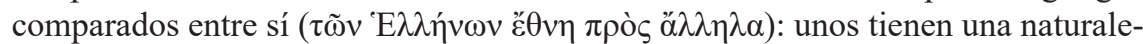
za unilateral; otros tienen combinadas esas dos facultades [coraje e inteligencia]. ${ }^{18}$

Por ello, en este artículo partimos de la base de que griego es un término polisémico, de carácter identitario, cuyo significado depende absolutamente de los contextos en los que se emplee, cambiando de uno a otro ${ }^{19}$ No obstante, lo que es innegable es que las Guerras Médicas suponen un punto de inflexión ideológico en cuanto a categorización del Otro y del Nosotros se refiere en el mundo griego, y que, al menos en el discurso de Heródoto, la religión es considerada un elemento básico de dicha categorización, y en ella vamos a centrarnos.

\section{Religión e identidad en la Grecia Antigua}

Antes veíamos cómo para el propio Heródoto son las creencias, los ritos y las prácticas religiosas las que, más netamente, separan la civilización (griega), que respeta y venera a sus dioses y sus templos, y la barbarie (persa), poseída por la hybris y el afán destructivo que la acompaña. Ahora bien, ¿hasta qué punto Heródoto refleja en su discurso una imagen extendida de lo que significaba ser griego o, por el contrario, la construye teniendo en cuenta los intereses de las elites atenienses? ¿Las prácticas religiosas constituyeron entonces un muro divisorio entre griegos y persas o son empleadas por el de Halicarnaso como una manera de legitimar la ideología de los griegos enfrentados a los persas, afeando de paso el colaboracionismo o la neutralidad de muchos otros griegos? ¿Tan importante fue lo religioso a la hora de definir lo griego y tan homogéneas sus prácticas y creencias ${ }^{20}$ como para que todos (con las dificultades aparejadas de definir ese "todos") las reconocieran? ¿Marca la religión únicamente semejanzas entre griegos o es también vehículo de discordia y enfrentamientos entre ellos, como es evidente que lo fueron las actuaciones políticas? ¿Hay diferencias entre los modos en los que se emplea la religión para definir la identidad

\footnotetext{
Arist. Pol. 1327 b 29-34.
}

19 Ya que este artículo se centra en la religión como criterio de identidad en la Grecia clásica y no propiamente en la construcción de la helenicidad en su conjunto, para un análisis más profundo de lo que implica la categoría "griego" y los cambios de significado a los que se ve sometida, así como las diferentes posibilidades de descripción y adscripción de la misma (identitaria, étnica, etc.) y sus implicaciones históricas, remito a obras anteriores, que sirven como base para desarrollar este trabajo, tales como CARDETE 2004; 2005a y b; 2007a y b; 2009; 2010, 127-180; 2011.

20 Aunque el término creencia no tiene un equivalente en griego clásico, como tampoco lo tiene el término religión, lo empleo en este artículo porque considero que refleja bien las relaciones establecidas entre los griegos y sus dioses, mitos, ritos y cultos, asumiendo la existencia y presencia de las fuerzas divinas y sus complejas relaciones con el mundo humano, que sólo encuentran sentido pleno (y coherencia interna) en la práctica religiosa, ya que tanto la creencia y el mito como el rito y el culto se encuentran y definen en la acción (BRÜCK 2007, 281-288; Christensen 2009, 14; Sorensen 2013, 12-13). Creo que los intentos de cuestionar o incluso suprimir el concepto de creencia de la religiosidad griega (BURKERT 1995, 205; CHRISTENSEN 2009, 20; VEYNE 1987) son consecuencia de una visión racionalista e ilustrada de la religión griega que nos aleja de su comprensión (CARDETE 2016, 35). 
panhelénica y los modos en los que se emplea para definir identidades más reducidas como las subhelénicas y cívicas, sin olvidar que todas ellas coinciden en tiempo y espacio y no son excluyentes entre sí? Son preguntas complejas, con muchas ramificaciones y llenas de matices y, por lo tanto, no pueden contestarse con respuestas simples, sino con un ejercicio de análisis que ahora pasamos a desarrollar.

\subsection{El nivel panhelénico: ¿religión griega o religiones griegas?}

Heródoto parece calificar a la religión griega como un conjunto de prácticas y de lugares de culto. Sobreentendemos que existen también unos dioses y héroes comunes. Pero, ¿qué ocurre cuando comunidades consideradas griegas por otros motivos que no sean específicamente el religioso (culturales, políticos, geográficos, lingüísticos...) desarrollan ritos heterodoxos para honrar a dioses comunes? ¿Siguen siendo consideradas griegas aunque lleven a cabo prácticas que no comparten con las demás y que, incluso, son despreciados por el resto? ¿Es utilizado en ese caso el culto/rito "anómalo" como una negación de la helenicidad o simplemente se ignora y/o se acepta la diferencia?

Un caso muy ilustrativo al respecto es el de los famosos sacrificios humanos dedicados al Zeus Liceo en Arcadia. Sin entrar en el peliagudo tema de la veracidad de los sacrificios del Liceo, ${ }^{21}$ centrémonos en las consecuencias de su supuesta existencia. El Minos pseudoplatónico, por ejemplo, se indigna ante el hecho de que aquellos que se llaman a sí mismos griegos practiquen tales aberraciones, propias de bárbaros, ${ }^{22}$ y Teofrasto, en un fragmento conservado por Porfirio, los compara con los sacrificios cartagineses. ${ }^{23}$ Sin embargo, no hay evidencia alguna en las fuentes que indique que los arcadios fueron considerados menos griegos por este hecho, ni siquiera de que los autores antiguos se plantearan que una reprobación tan radical pudiera llegar a ocurrir, lo que demuestra que la religión no constituía un criterio estricto de participación o exclusión de la identidad griega. El propio Pausanias, rendido admirador del mundo arcadio, al que dedica el libro más voluminoso y profuso de su Periégesis, se limita a comentar, un tanto ambiguamente, que sobre el altar de Zeus Liceo se continuaban realizando sacrificios y que "no era agradable para mí preguntar indiscretamente sobre este sacrificio. Sea como es y como lo fue desde el principio". ${ }^{24}$

La variabilidad en la importancia concedida a lo religioso en la configuración identitaria no se percibe sólo cuando son pueblos tenidos por griegos los que infringen supuestos cánones religiosos, sino también cuando pueblos no considerados

21 Sobre el particular remito a los estudios clásicos de BONNECHERE 1994 y 2009; BremMER 2007; BURKERT 1983; Georgoudi 1999; Halm-Tisserant 1993; Henrichs 1981; Hughes 1986; Jost 2002 y 2005, así como a análisis anteriores como CARDETE 2005a, 184-190; 2006a y en prensa. Aunque hasta hace unos meses se había sostenido que no existía ningún resto de sacrificio humano en el Liceo, pues se había llegado en las excavaciones hasta la roca madre del temenos sin señal alguna de ello (RomAno - Voyatzis 2010, 46), en los trabajos arqueológicos del verano de 2016 del Mount Lykaion Excavation and Survey Project, dirigido por los Profs. Anna Karapanagiotou, David Romano y Mary Voyatzis, se han encontrado restos humanos, concretamente un enterramiento, muy cercano al altar, en lo alto del monte San Elías, datable en el s. XI a.C. Aún es pronto para poder considerarlo evidencia de sacrificio humano, pero es la primera vez que se hallan huesos humanos en el Liceo (más información en http://lykaionexcavation.org/site/research-highlights).

22 Pse. Pl. Min. 315C.

23 Porph. Abst. 2.27.2.

24 Paus. 8.38.7. 
griegos por sus vecinos adoptan prácticas religiosas helenas y, sin embargo, siguen siendo tenidos por bárbaros. Es el caso de los sicanos y el culto a Minos y Afrodita en Cámico.

Según la leyenda griega, Minos, furioso con Dédalo por haber posibilitado los encuentros extramatrimoniales de Pasífae con un toro, lo persigue hasta Sicilia, donde se había refugiado el inventor. Allí, Dédalo es defendido por Cócalos, rey de Camico, quien acaba matando a Minos. Los huesos de Minos fueron enterrados junto a un templo dedicado a Afrodita ${ }^{25}$ por los cretenses que habían acompañado a su rey a Sicilia. Diodoro ${ }^{26}$ nos aclara que los indígenas rindieron culto en el santuario durante generaciones pensando que estaba, únicamente, dedicado a la diosa. Así pues, los sicanos participaban junto con los griegos en un culto creado por griegos en honor a una diosa griega y, sin embargo, eso no les convierte, en absoluto, en griegos, ni siquiera les acerca a ellos, puesto que los sicanos son presentados como meros receptores pasivos de tradiciones que, supuestamente, recrean su pasado y que, sin embargo, no proceden de él, puesto que han sido construidas por los propios griegos. ${ }^{27}$

Pero si hay algo que identifique a la religión griega a un nivel macro, eso son, precisamente, los llamados cultos panhelénicos en los que, teóricamente, participaban todos aquellos que podían ser considerados griegos por sus semejantes, quedando excluidos, total o parcialmente, el resto, así que es importante centrarnos en un culto panhelénico para comprobar cómo funcionaba la religión a este nivel en la configuración de la identidad.

Uno de los casos más paradigmáticos es el de los Juegos Olímpicos, en los que supuestamente sólo podían participar griegos.$^{28} \mathrm{De}$ ser esto cierto, podría parecer que la religión ("comunidad de santuarios y de sacrificios a los dioses", que diría Heródoto), efectivamente, funcionaría en el mundo griego como un cemento identitario de primer orden, pero no podemos olvidar que las mujeres griegas también participaban, en general, de la comunidad de santuarios y de sacrificios a los dioses que caracterizan al ethnos griego según Heródoto y, sin embargo, estaban excluidas de participar en los Juegos Olímpicos, como muy bien refleja Pausanias cuando cuenta la historia de Calipatira ${ }^{29}$ (el sesgo de género no es en este caso menos importante que el identitario). Así pues, la realidad siempre es compleja, y las afirmaciones taxativas no responden realmente a la riqueza de la organización y significación olímpicas.

Para empezar, como defiende Hall,$^{30}$ no hay pruebas de que la obligatoriedad de ser reconocido como griego pueda extenderse a ningún otro culto panhelénico. De hecho, cuando Heródoto ${ }^{31}$ enumera los oráculos griegos (Delfos, Abas, Dodona, los santuarios de Anfiarao y Trofono y el milesio de los Bránquidas) a los que envió emisarios Creso de Lidia para saber si debía entrar en guerra contra los persas, el de Halicarnaso no muestra sorpresa alguna porque un extranjero recurriera a dicha práctica ni lo desaprueba de ninguna forma. Todo lo contrario, Heródoto incluso registra cumplidamente la respuesta completa que Delfos dio a los emisarios (y que tanto agradó a Creso) y constata la existencia de las demás, aunque no tuviera acceso

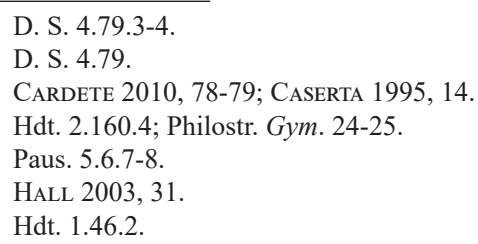


a ellas, señalando que la del oráculo de Anfiarao también había sido del gusto del rey lidio. ${ }^{32}$

Incluso partiendo del hecho de que los Juegos Olímpicos, a un nivel representativo, eran una competición exclusivamente para hombres griegos libres, eso no supone que la religión tenga que funcionar siempre y en todo caso como un criterio identitario evidente y no contradictorio, y ello por varios motivos.

En primer lugar, el santuario de Olimpia no se acaba en los Juegos y no hay indicio alguno de que estuviese vedado a los no griegos en otro ámbito que no fuera el de la competición o los cargos públicos, que sólo constituyen una parte del culto, aunque se tiendan a tomar por el todo. De hecho, el santuario se remonta al menos al s. X a.C., ${ }^{33}$ mientras que los Juegos Olímpicos propiamente dichos, en un primer momento más regionales que panhelénicos, ${ }^{34}$ no comienzan antes de mediados del s. VIII a.C. - principios del s. VII a.C. (con la referencia, más mítica que histórica, del 776 a.C.). ${ }^{35}$ De la misma forma, aunque sabemos que las mujeres no participaban en los Juegos, sí que lo hacían activamente en la vida del santuario y, de hecho, las eleas celebraban allí sus propios Juegos, llamados Hereos, también cada cuatro años, aunque en fechas distintas a los Olímpicos. ${ }^{36}$ Además, no cualquier griego podía ejercer cualquier cargo, ya que jueces y figuras oficiales como los Theorodokoi o los Hellanodikai se reservaban, en general, para los eleos, ${ }^{37}$ sin que eso implique, obviamente, que se trataba de un culto exclusivamente eleo, por mucho que fuera Elis quien administrara el santuario. ${ }^{38}$ Y no podemos olvidar la inmensa cantidad de ofrendas que se hacían en el santuario, entre las que se incluyen las de numerosas poleis que dedicaban los despojos del enemigo, siendo este otra polis o comunidad griega, sin que ello les pareciera a ninguno de los contendientes una incoherencia identitaria (en esos momentos la religión funcionaría como criterio identitario cívico al tiempo que contribuiría a la disolución del criterio identitario panhelénico): así ocurre con la propia Elis cuando destruyó Pisa y utilizó los restos de la victoria para levantar, nada menos, que parte del templo y la estatua de Zeus. ${ }^{39}$

Ciertamente, los Juegos Olímpicos no pueden equipararse al concepto moderno de deporte, sino que tienen una clara trascendencia religiosa (y política) que no se limita al papel de los atletas, sino que se extiende también al público asistente. Por lo tanto, parte del significado religioso de la fiesta estaba abierto a gentes muy diversas que no tenían por qué sentirse ni ser vistas como griegas y que, sin embargo, muy bien podían verse identificadas momentáneamente con el Zeus Olímpico y los ritos aparejados. A este respecto es significativa la anécdota que cuenta Heródoto ${ }^{40}$ en la

Hdt. 1.47-48.

Morgan 1990, 26.

Morgan 1990, 61-105; SinN 2014, 124.

Morgan 1990, 47-49; SinN 2014, 122-126. Cargos cultuales relacionados con el santuario de Zeus, como iareis, iaromaoi, manteis o theokoloi no tienen relación alguna con los Juegos, pero aparecen varias veces citados en las leyes sacras del templo (GoLden 1998, 15), lo que redunda en que Olimpia es mucho más que sus Juegos.

36 Paus. 5.16.2-8. Sobre la posibilidad de que las Herea estuviesen abiertas a muchachas no eleas remito a KYLE 2014, 264-265.

37 Kyle 2007, 114-155; Mann 2014, 277; Miller 2004, 156; Nielsen 2014, 136-138.

38 Paus. 6.24.3; Th. 5.49.1.

39 Paus. 5.10.2. Ver también Paus. 5.10.4 (victoria lacedemonia de Tanagra), 5.24.4 (victoria elea frente a los arcadios) o 5.26 .1 (victoria de los naupactios sobre los acarnianos y de los mesenios sobre Esparta en Esfacteria).

40 Hdt. 2.160. La respuesta de los egipcios es que los eleos deberían dejar de participar en los Juegos, dejándolo solo como una competición para extranjeros (xenoi, es decir, no miembros de la polis, marcando la diferencia 
que una delegación elea se encamina hasta Egipto, a la corte del faraón Psamis, para que los egipcios, tenidos por inmensamente sabios, les recomendaran alguna manera de mejorar la gestión y celebración de los Juegos. Y el propio Píndaro canta en su Olímpica I a los "forasteros innúmeros" que visitan el altar de Zeus. ${ }^{41}$

En segundo lugar, porque si ser reconocido como griego por el resto de participantes era requisito imprescindible para competir en los Juegos, no lo era en menor medida pertenecer a una comunidad griega (mayoritariamente una polis) que respetase las leyes olímpicas, influidas por los eleos en gran medida. ${ }^{42}$ En ocasiones incluso, debido a enfrentamientos políticos, determinadas poleis quedaban excluidas de la competición, por muy griegas que fueran consideradas, como le ocurrió a Esparta en el 420 a.C. Ante la imposibilidad de competir como espartano Licas, hijo de Arquesilao, se presentó a la carrera de carros como beocio, recuperando posteriormente su identidad espartana, ${ }^{43}$ lo que demuestra, primero, la ductilidad de las adscripciones y que lo importante no era tanto ser griego, sino ser miembro de una comunidad reconocida políticamente y sin cuentas pendientes con quienes controlaban el santuario y, segundo, la tensión evidente, no sólo en el plano político, sino también identitario y religioso, entre Olimpia como santuario panhelénico y Olimpia como santuario eleo. ${ }^{44}$ Tal prestigio podía llegar a aportar la victoria en los Juegos a la polis del vencedor que algunas ricas y poderosas, como Siracusa, desarrollaron una política de "fichajes" para asegurarse el podio. ${ }^{45}$

Además, hay que tener en cuenta que ni todas las poleis podían participar en la misma medida ni todos sus campeones tenían las mismas oportunidades de ganar, ya que representar a una polis débil, pequeña o mediocre iba en detrimento del prestigio del atleta y actuaba en contra de sus posibilidades de hacerse con la victoria, ${ }^{46}$ como puede apreciarse en los listados de vencedores. ${ }^{47}$ Las poleis, empleando su poder político y su unidad estatal, solían enviar una embajada pública (los theoroi) para que realizara diversos rituales antes de los Juegos, de la misma forma que las autoridades olímpicas (y esto se hace extensible al resto de santuarios panhelénicos) enviaban a sus representantes a las poleis implicadas en las festividades. No obstante, las más pequeñas o menos ricas no siempre contaban con esta posibilidad y, por lo tanto, los Juegos Olímpicos, al tiempo que marcaban una unidad de lo helénico, contribuían a poner de manifiesto las diferencias entre griegos y a jerarquizarlos, no por sus creencias, sino por su acceso a los recursos.

Lo mismo sucede a la hora de elegir a los campeones de cada polis: aunque teóricamente los atletas podían proceder de todos los estratos sociales, la mayor parte

abismal entre ser o no ser ciudadano y no tanto entre ser y no ser griego; remito también a n. 80), pues de ese modo serían más imparciales en su gestión.

41 Pi. O. 1.93.

42 Paus. 624.3 .

43 Th. 6.49-50.

44 Sobre las dificultades de aunar el factor local y el factor panhelénico en Olimpia remito a NIELSEN 2007, 29-54 y 2014.

45 Paus. 6.2.6 y 3.11.

46 Isoc. Ep. 16.33. Así pues, la encendida defensa herodotea de la areté, que teóricamente era lo único que movía a los griegos a participar en los Juegos Olímpicos, frente a las ansias materiales de los persas, incapaces de entender que el premio fuera una simple corona y no riquezas (Hdt 8.26.2-3), no deja de ser una construcción retórica aristocrática alejada de las realidades pecuniarias que rodeaban a los Juegos, tanto en la preparación como en la celebración, así como sus causas y consecuencias aparejadas.

47 Christensen 2007; Moretti 1957. 
eran aristócratas (o, al menos, asumían la ideología aristocrática) que empleaban los Juegos Olímpicos (y otras muchas competiciones atléticas, panhelénicas, regionales o incluso locales) como una expresión de la solidaridad de clase, creando relaciones horizontales suprapolíadas sobre la base de las relaciones verticales estatales. ${ }^{48}$ Incluso cuando empieza a "democratizarse" la participación atlética en los Juegos, especialmente a partir del s. V, las mayores posibilidades de victoria las tenían los aristócratas, con más tiempo para entrenar, mejores entrenadores y mejor preparación física, ${ }^{49}$ por no hablar del rechazo cuasi moral que provocaba entre las elites que quienes no formaban parte de ellas pudieran hacerse un hueco en los Juegos Olímpicos (lo cual demuestra, ciertamente, que ocurría), ${ }^{50}$ o las formas absolutamente imbuidas de espíritu aristocrático con las que se celebraba a los vencedores. ${ }^{51}$

Ejemplo muy significativo a este respecto es la competición que se establece entre poleis y entre individuos de las clases privilegiadas por realizar ofrendas más suntuosas que las del vecino en los santuarios panhelénicos, especialmente en Delfos y Olimpia. En ambos casos es muy llamativa, por ejemplo, la cantidad de exvotos ofrendados por donantes procedentes de Sicilia y la Magna Grecia, ${ }^{52}$ que tratan de ese modo de interactuar con las elites continentales empleando para ello no una identificación estricta con un concepto tan vago como el de "helenicidad", ni mucho menos una autopercepción común, sino cierta conciencia de comunidad cultural y, sobre todo, lazos de solidaridad de clase dirigidos por intereses coyunturales. ${ }^{53}$ Destaca el caso de los reyes lidios que, evidentemente, no eran griegos y que, sin embargo fueron los únicos, junto con los tiranos dinoménidas, ${ }^{54}$ que realizaron ofrendas de oro en Delfos, ${ }^{55}$ como medio de conseguir proyectar su poder e influencia más allá

48 Albanidis 2004, 44-45; De Polignac 1999-2000; Hölscher 2011, 53-54; Morgan 1990, 191-193, 203-205, y 2007, 120; NiCHOLSON 2005.

49 Arist. Pol. 1297a 29-35; Isoc. Aerop. 44-46; Pl. Lg. 806d-807e. Plutarco (Eum. 1.1-2) cuenta una anécdota interesante a este respecto al comienzo de su relato sobre Eumenes: recoge la versión de Duris, según la cual, a pesar de que el padre de Eumenes había sido un humilde carretero, el hijo había recibido una estupenda educación en lo intelectual y en la palestra, lo que le granjearía finalmente el favor de Filipo. No obstante, él mismo cree que es más probable que Filipo y el padre de Eumenes fueran amigos, y de ahí el interés del rey por el muchacho. Por lo tanto, Plutarco pone en duda que el hijo de un carretero pudiera conseguir la formación física y mental necesaria para codearse con reyes o ganar competiciones. Sobre entrenadores, jinetes y otras figuras necesarias para alcanzar la victoria pero mucho menos representadas en las fuentes, precisamente por su falta de status aristocrático, remito a MANN 2014 y NiCHOLSON 2005.

50 E. Autol. Fr. 282; X. Ages. 9.6-7. No obstante esta oposición, a partir de época helenística y durante el mundo romano es cada vez más frecuente la aparición de atletas más profesionales (en el sentido más de "empleados" que de "iguales socialmente") (Albanidis 2004, 45; Miller 2004, 207-215). Sobre la polémica acerca del grado de "profesionalización" y de "democratización" de los juegos remito a CHRISTENSEN (2014), que presenta un buen estado de la cuestión con bibliografía, y a KYLE (2007, 205-216). No es ajeno a este cambio, obviamente, el proceso de profundas transformaciones que vive el sistema políado y que da lugar a un mundo griego muy distinto del arcaico y del clásico, en el que la polis no es el centro de la organización comunitaria.

51 No sólo se trata de los epinicios pindáricos, sino de todo un conglomerado de literatura, imágenes, epigrafía y formas de celebración (premios, reconocimientos públicos, procesiones...) que cantan la gloria de la victoria en un universo marcado por valores aristocráticos clásicos como la areté (GoldEN 1998, 74-102; NeILs 2014; Nicholson 2014; Pleket 2014).

52 ANTONACCIO 2001, 134-135.

53 CARDETE 2010, 132.

54 Tras la victoria de Hímera sobre los cartagineses, Gelón, tirano de Siracusa, ofrendó en Olimpia un thesauros compuesto por una estatua de Zeus y tres corazas de lino (Paus. 6.19.7). Así mismo, depositó en Delfos un trípode áureo de 16 talentos y una Niké de oro (Ath. 6.231e-232b; D. S. 11.2.7). El poeta Baquílides (Ep. 3) le dedicó a Gelón una oda alabando, precisamente, su poder y su capacidad de visibilizarlo.

55 Heródoto (1.50-51) narra con todo lujo de detalles las espectaculares ofrendas que Creso depositó en Delfos, entre las que destaca continuamente el oro en diversas formas: lechos repujados en oro y copas de oro destinadas 
de las esferas local y regional, independientemente de que se les considerara o no miembros de la comunidad griega o incluso bárbaros.

En tercer lugar, porque aquello que diferenciaba al griego del que no lo era no se circunscribía a la comunión de creencias y prácticas religiosas, sino a factores muy variados entre los que estos solo eran un elemento más, y no siempre destacado. Recordemos, por ejemplo, el caso de Alejandro I de Macedonia. Cuando este rey macedonio quiso participar en los Juegos Olímpicos, los helanódicas discutieron si era o no era griego, algo más amplio (y complejo de definir) que si practicaba sacrificios al modo griego o adoraba a los dioses griegos. Alejandro defendió su helenicidad recurriendo a su supuesta descendencia de antepasados argivos, y Olimpia terminó aceptándole basándose en dichos criterios genealógicos ${ }^{56}$ que imbrican a la perfección lo religioso y lo político y, además, son absolutamente maleables. De hecho, mientras que Tucídides, ${ }^{57}$ inmerso en un mundo en el que las diferencias venían marcadas por la pertenencia subhelénica al grupo dorio o al jonio, asume sin grandes problemas la helenicidad de Alejandro I, al que cree descendiente de los Teménidas argivos, ${ }^{58}$ Demóstenes, comprometido en la tarea de no permitir a Filipo I controlar Atenas, insiste en que Filipo no sólo no es griego, sino ni siquiera bárbaro, pudiéndose sólo

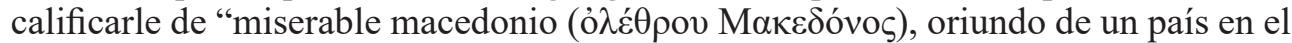
que antes ni comprar un esclavo diligente era posible". 59

Finalmente, Alejandro I pasa a ser catalogado como Filoheleno y, por lo tanto, como no griego, primando la necesidad política sobre el criterio religioso, que queda relegado. Además, haciendo uso de los mismos criterios, los griegos se tendrían que haber visto obligados a aceptar a los propios persas como griegos, ya que, como decíamos antes, los argivos habían empleado el recurso a una genealogía común con los persas para mantenerse neutrales durante las Guerras Médicas y el mismo Jerjes también utilizó referencias genealógicas para hacer su mandato sobre los jonios menos gravoso. ${ }^{60}$ Obviamente, el argumento religioso no siempre era válido per se, dependía de la complejidad del contexto y de las interrelaciones, pudiendo unir o separar a conveniencia.

Siguiendo con la irrupción de los macedonios en los asuntos de la Grecia continental, los discursos de Isócrates son muy útiles para advertir la permeabilidad de lo religioso como criterio identitario panhelénico. Apenas un siglo después de la declaración herodotea sobre la "comunidad de santuarios y de sacrificios" como elementos consustanciales al espíritu griego, los criterios de identidad varían con las circunstancias y la religión, aunque continúa siendo empleada como un valor a tener en cuenta, no ocupa ya una posición tan relevante a la hora de caracterizar a lo griego.

a arder en una inmensa pira junto a vestidos de púrpura y túnicas lujosas; 117 lingotes de oro, dos estatuas de oro representando a un león y a una mujer, una crátera de oro o un aguamanil de oro. El santuario de Anfiarao también recibió su magnificencia áurea en forma de un escudo y una lanza de oro (Hdt. 1.52). Ver AmANDRY 1987, 81-92; JACQUEMIN 1999, 287-288.

56 Hdt. 5.22

57 Th. 2.99 .3 y 5.80 .2 .

58 No obstante, su opinión sobre la helenicidad de los macedonios no es clara (quizá porque no se plantea seriamente el tema y, simplemente, desarrolla ideas que, no por ser contradictorias, dejan de estar extendidas), ya que en otros momentos de su discurso los lista junto a pueblos extranjeros llamados bárbaros, como los caones, los tesprotos o los molosos (Th. 2.80.5-7), o bien diferencia sus contingentes de los de hoplitas griegos (Th. 4.124.1) o los califica, directamente, como bárbaros (Th. 4.126.3).

59 D. Phil. 3.31 .

60 Haubold 2007. 
Isócrates, de hecho, desarrolla un modelo de definición étnica que aboga por la inclusión, llegando a declarar que "son llamados helenos no aquellos que tienen nuestro mismo origen, sino aquellos que tienen en común con nosotros nuestra cultura". ${ }^{61}$ El cambio no procede, como podría pensarse ingenuamente, de una mayor tolerancia en la visión del Otro, sino de una serie de intereses socio-políticos y económicos que conectaban con las aristocracias tradicionales atenienses y el creciente ascenso de los macedonios como poder a tener muy en cuenta en Grecia.

La Atenas del s. IV a.C. había visto mermado su poder tras la derrota ante Esparta en la Guerra del Peloponeso en mucha mayor medida que sus ambiciones de control y crecimiento. Isócrates representa a un grupo de oligarcas tradicionalistas que temen que la lucha por recuperar el sistema democrático pre-bélico pueda acabar en un proceso de confiscación y reparto de tierras, fatal para sus intereses económicos y sus aspiraciones políticas. Para conjurarlo, al tiempo que aboga por el desmantelamiento progresivo de la democracia radical, muy limitada ya por el auge de la patrios politeia y las reformas políticas y fiscales ${ }^{62}$ agita el fantasma del miedo al persa y la bandera de la venganza contra el invasor extranjero, ${ }^{63}$ encarnada en la humillante Paz del Rey (386 a.C.), que obligó a Atenas a devolver las ciudades griegas de la Jonia al control persa. ${ }^{64}$

Pero para recuperar poder y enfrentarse a los persas, Atenas necesitaba aliados, y los oligarcas representados por Isócrates los encontraron en los macedonios. Convencidos de que sólo Filipo sería capaz de devolverle a Atenas el esplendor perdido, transformándola de nuevo en el ariete persa que la tradición ateniense se reservaba para sí casi en exclusiva ya desde Maratón, ${ }^{65}$ necesitaban superar el escollo que suponía que su paladín no fuera ateniense y, además, perteneciera a un pueblo del que ya a principios del s. V a.C., como vimos, se dudaba si era bárbaro o griego, dudas que se mantuvieron muy activas al menos hasta Queronea. ${ }^{66}$ Eliminando la barrera que suponía la ya trasnochada definición herodotea del ethnos griego (atenienses y macedonios no compartían, al menos no de una forma evidente para todos, ni comunidad de sangre, ni lengua, ni religión, ni usos, ni costumbres $)^{67}$ y centrándose en la

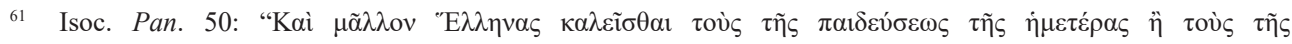

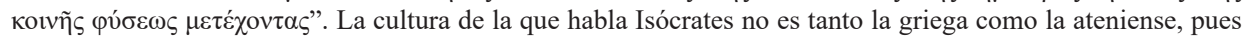
en el imaginario ático del s. IV una cosa es equiparable a la otra, incluso para su enemigo acérrimo, Demóstenes (SAÏD 2001).

62 Existe una candente división en la actualidad entre quienes cuestionan la profundidad de la crisis del s. IV a.C., incluso negando la posibilidad de que pueda emplearse, en puridad, el mismo término crisis, y quienes la defienden e insisten en sus devastadores efectos. No es mi intención debatir este extremo, puesto que excedería con mucho los límites de este análisis, pero no puedo dejar de señalar su existencia, remitir a un excelente y muy actualizado estado de la cuestión, sobre todo en lo que al campesinado se refiere, sobre el particular (GALLEGO - VALDÉs 2014, 213-232) e indicar que, en mi opinión, la crisis no sólo existió, sino que fue devastadora para los hoplitas y, sobre todo, para los thetes, víctimas principales de la reivindicación aristocrática de la patrios politeia y de la pérdida de derechos que llevaba aparejada.

${ }^{63}$ A pesar de la retórica ateniense anti-bárbara propia del s. IV a.C., Allen (2003) destaca que en los epígrafes que recogen los tratados firmados entre Atenas y otras poblaciones en este período se detecta bastante uniformidad entre el tratamiento que se le da a otros griegos y el que se le da a pueblos bárbaros. Por tanto, la imagen estereotipada del bárbaro como antagonista y prueba de la helenicidad de los griegos no deja de ser una construcción retórica explotada en determinados momentos y/u ocasiones $\mathrm{y}$, especialmente, por las fuentes literarias (HONGMAN 2007, 130).

64 Cartledge 1993, 51; Castriota 2000, 478-479; Fornis 2008, 298-327.

65 CARDETE 2011.

66 TredÉ 1991, 79.

${ }^{67}$ Las dudas sobre qué unía y qué separaba a griegos y macedonios no sólo las tenían los griegos antiguos, sino 
conducta (que puede aprenderse y, por lo tanto, adquirirse), Filipo pasaba a ser un mecenas digno de la helenicidad, lo cual no significaba que lo fueran también el resto de macedonios, sino sólo aquellos que se comportaran como si fueran griegos (es decir, en el pensamiento ático de la época, como si fueran atenienses). ${ }^{68} \mathrm{El}$ criterio "culturalista" es ahora mucho más decisorio en la definición de la helenicidad (atenocéntrica) que el religioso.

\subsection{El nivel subhelénico: dorios y jonios, entre el enfrentamiento y la reconciliación}

El nivel subhelénico precede cronológicamente al panhelénico ${ }^{69}$ y es uno de los primeros que se instrumentaliza en períodos de guerra y nos ofrece también significativos ejemplos de cómo el criterio religioso de identidad es maleable y difuso y puede servir al mismo tiempo como criterio de identidad incluyente y excluyente y variar, dependiendo de las circunstancias, su relevancia.

Durante las Guerras Médicas el eje opositivo básico del mundo griego se trazó con los persas, pero eso no impidió que jonios y dorios mantuvieran alzadas las lanzas y que, por ejemplo, la sacerdotisa de la Atenea Polias rechazara al rey espartano Cleómenes en su santuario alegando que era dorio, a lo que él respondió que no era tal cosa, sino aqueo. ${ }^{70}$ Se trata del mismo Cleómenes que rechazó el argumento de Aristágoras de Mileto, según el cual los espartanos debían ayudar a los jonios a liberarse de los persas porque tanto unos como otros compartían la misma sangre, ${ }^{71}$ algo con lo que los espartanos no parecían estar muy de acuerdo, ni siquiera en plena contienda contra el persa.

La facilidad con que unos y otros son adscritos o se adscriben a grupos identitarios distintos nos asombra mucho más a nosotros que a los griegos, puesto que no es un caso ni único ni aislado, como demuestra el ya comentado de Licas, el espartano transmutado en beocio y vuelto a ser espartano para poder competir en los Juegos Olímpicos. Así pues, como ya dijimos anteriormente, los lazos de solidaridad de clase funcionan como potentes generadores de identidades plurales y móviles que son, en primer término, relaciones políticas teñidas de elementos identitarios y, sólo después, algunas adquieren connotaciones étnicas. ${ }^{72}$

Un poco después del incidente de la Atenea Polias, a mediados del siglo V a.C., cuando aún no se habían desatado del todo las hostilidades entre Atenas y Esparta pero la tensión era más que evidente, una inscripción de Paros declara explícitamen-

que han llegado hasta nuestros días en forma de debate sobre la construcción de la identidad macedonia y su encaje con el mundo griego. La bibliografía es inmensa, pero remito a algunos títulos especialmente interesantes sobre cuestiones lingüísticas, genealógicas, religiosas y culturales tales como BorZA 1990; DASCALAKIS 1983; Hall 2001; Hammond 1989; Lane Fox 2011; Roisman - Worthington 2007; Sheedy 2007; Tracy 2003.

68 CARDETE 2006b, 190-191.

69 Como defiende Hall $(2002$, 56), aunque la retórica identitaria de las Guerras Médicas dé a entender que los griegos existían desde tiempos inmemoriales, las categorías sub-helénicas son anteriores y propician, precisamente, la posibilidad de constituir discursivamente un ethnos griego a principios del s. V. a.C. De hecho, el propio Tucídides (1.3.1-3) insiste en que el término helenos no es una denominación que pueda imponerse a todos, ni siquiera durante la Guerra de Troya, y que por ello Homero apenas lo utiliza y, en cambio, sí que habla profusamente de dánaos, argivos o aqueos.

70 Hdt. 5.72.3.

71 Hdt. 5.49.2.

72 Cardete 2016, 132; Hölscher 2011, 54-55; Hornblower 2008; Osborne 2012. 
te que se rechaza a los xenoi dorios en el santuario de Coré. ${ }^{73}$ Los cultos cívicos, y especialmente los más unidos a la conformación y sostenimiento del estado, rechazan a aquellos a los que consideran extranjeros y enemigos, impidiéndoles el acceso a unos dioses que, por mucho que sean comunes, se han instrumentalizado como arma de oposición.

Que la religión no es una creencia abstracta, sino una construcción ideológica y profundamente social en la que los intereses y necesidades coyunturales de toda índole tienen más peso que supuestos principios estructurales comunes de cariz espiritualista, lo demuestra también la utilización de la figura de Ión en el enfrentamiento entre dorios y jonios. Eurípides escribe una tragedia titulada precisamente Ión en el 412 , en medio de la guerra de Decelia y con la moral ateniense muy baja. Esta obra da un vuelco a las genealogías tradicionales (que hacían a Ión hijo de Juto y Creúsa) y convierte a Ión en fruto de la violación que Apolo perpetra en Creúsa, hija de Erecteo y descendiente, por tanto, del mítico rey Cécrope. Los niveles de análisis del mito son múltiples, ${ }^{74}$ pero centrémonos en tres.

Primero, los griegos, con su "comunidad de santuarios y de sacrificios", han desaparecido como grupo unido y se ven enfrentados, precisamente, por cuestiones genealógicas, mitológicos y religiosas, aparte, obviamente, de políticas.

Segundo, la autoctonía ateniense, y con ella la ideología imperialista que había conducido a Atenas a la guerra, se ve reforzada con este giro de los acontecimientos, que pretende, ahora sí, promover una unidad, pero no entre los griegos, sino entre los jonios, y no por las semejanzas que los unen, sino por una común oposición a los dorios, de modo que el panhelenismo se ve fragmentado en categorías subhelénicas.

Tercero, entre una posición antagónica y otra, Eurípides parece tender un puente de unión apoyándose en aquello que le había servido para fomentar la separación: la religión. La nueva genealogía de Ión enfrenta, marcando la supremacía de los atenienses autóctonos sobre los dorios, más jóvenes ${ }^{75} \mathrm{y}$, por lo tanto, con menos derechos sobre la tierra, pero también lanza un guiño de reconciliación, ya que Ión se presenta como hijastro de Juto y hermanastro mayor de Doro, fruto de la unión entre Juto y Creúsa. La primogenitura de Ión convertía a sus descendientes, los atenienses y los jonios, en precursores de los dorios, pero también les hacía compartir la misma sangre, en un giro de lo más dramático.

\subsection{El nivel cívico: la religión como autodefinición y oposición}

La polis es la unidad central de organización e identificación política y religiosa en la Grecia clásica. Los ciudadanos y habitantes de una polis enarbolan la bandera de sus dioses y sus héroes como una forma primaria de autoidentificación, que en ocasiones les une y a veces les separa de los ciudadanos y habitantes de otras poleis, sin que por ello la identidad políada sea inamovible. De hecho, ya hemos visto que no son extraños los casos de paladines olímpicos que, en su participación en unos juegos

IG 12.5.225. Ver Butz 1996.

74 El tratamiento que da Eurípides a la genealogía de Ión ha sido objeto de múltiples estudios cuyo análisis excedería el marco de este artículo, pero que creo preciso señalar. Para un tratamiento en profundidad remito a excelentes trabajos como los de Swift (2008), Zacharia (2003) o Zeitlin (1989), así como a Valdés (2006), que defiende la hipótesis de que la relación paterno-filial entre Apolo e Ión es anterior a Eurípides.

75 En la genealogía helénica tradicional Doro, Juto y Eolo eran hijos de Helén, mientras que Aqueo e Ión eran nietos, luego los dorios eran anteriores a los jonios, al contrario que en la genealogía de Eurípides. 
eminentemente religiosos en los que la polis de origen tiene una gran trascendencia ideológica, cambian esta por otra de adopción, sin que de ello resulte ningún castigo ni carga ingrata más allá del desprecio de algunos intelectuales cuando la causa es espuria. $^{76}$

Es cierto que tampoco a un nivel cívico encontramos ni igualación ni homogeneidad en la práctica religiosa, ya que los diferentes miembros de la polis se jerarquizan no solo por sus propiedades, estatus, género, edad o actividades, sino también por su acceso a determinados cultos. De hecho, una distinción básica, intrínseca a la constitución de la polis, es la que discrimina a los ciudadanos de los que no lo son, y en la constitución de esa diferencia tiene mucho que ver la participación de unos y otros en distintos cultos o en formas diferentes en el mismo rito. En ocasiones la segregación es total, de modo que hay cultos exclusivos para ciudadanos y cultos propios de grupos con un acceso restringido a la ciudadanía o sin acceso alguno, bien sea por su género (quizá el caso más conocido sea el de las Tesmoforias atenienses, cuyo exclusivismo femenino es satirizado por Aristófanes en la famosa comedia del mismo nombre) o por su condición social (las Calqueas, por ejemplo, son una fiesta en honor a Hefesto reservada a los artesanos). ${ }^{77}$ En otras, como las fiestas más importantes de las diferentes poleis, toda la comunidad participa, pero no de la misma manera, como queda patente, por ejemplo, en la procesión de las Panateneas.

No obstante, estas diferencias en el seno de la polis, avaladas por las prácticas religiosas, son una forma (aristocrática y desigual, eso sí) de constituir al grupo y aportarle una identidad, por mucho que la mayoría obtenga muchas menos ventajas que la elite, de modo que podemos afirmar que es en el espacio políado donde encontramos mayores muestras de la utilización del criterio religioso como elemento básico de conformación de la conciencia de grupo. Eso sí, la polis se fortalece al mismo ritmo en que se debilitan las lealtades suprapolíadas y panhelénicas, pues la polis es el estado y la patria, la referencia política principal (y en ocasiones única) para la mayor parte de los denominados griegos, ${ }^{78}$ hasta el punto de que el término xenos suele emplearse para calificar a aquel que no pertenece a la polis, ${ }^{79}$ mientras que bárbaro es el que, además de no pertenecer a la polis, genera una buena dosis de extrañamiento cultural (generalmente negativo) ${ }^{80}$

Las epifanías militares son un caso muy evidente de utilización de lo religioso como arma arrojadiza entre poleis. Los dioses y héroes supuestamente comunes de

76 Así, Pausanias (6.18.6) refleja con reprobación la participación de Sotades en la $100^{\circ}$ Olimpiada (380 a.C.) como efesio cuando en la anterior lo había hecho como cretense, su adscripción de origen, y todo ello por haber sucumbido al soborno de los efesios. Más allá de la opinión de Pausanias, Sotades se alzó con la victoria en ambas carreras. Ver también n. 45. Distinto es el caso de Ergóteles, natural de Cnosso pero obligado a exiliarse por una revuelta. Habiendo hallado acogida en Hímera, a Pausanias (6.4.11) le parece lógico que ganara la carrera larga en Olimpia como himereo y no como originario de Cnosso.

77 Sobre las Calqueas remito a VALDÉs 2015.

78 Como ha defendido Hongman $(2007,129)$, para la comprensión del mundo griego es mucho más determinante la diferencia entre ciudadano y no ciudadano, es decir, el nivel cívico, que la diferencia entre griego y bárbaro, es decir, el nivel panhelénico. Ver también Cardete 2005b; Duplouy 2006; GeHrke, 2010, 20; LÉvy 1991, 69; Nielsen 1999 y 2002, 113 y 155, 59; Osborne 2012; Roy 2009, 60-61; SAÏD 2001, 286; Sebillotte CuCheT 2006.

79 Por ejemplo, Píndaro (I. 50-51) distingue entre la lengua de los ciudadanos y la de los extranjeros

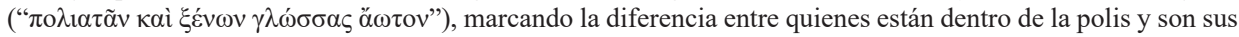
ciudadanos y todos los demás, que entrarían dentro de la amplia categoría de extranjero.

80 MogGi 1992, 53, y 1991, 31. En el caso de los espartanos, el término suele hacer referencia sólo al bárbaro, no al que procede de otra polis (Hdt. 9.11.3 y 55.2). 
la religión griega, que unían a todos los griegos en mayor medida que otros criterios identitarios, se convierten en defensores de la causa de una ciudad, por la que luchan sin piedad frente a otros griegos que también les rendían culto. Los ejemplos son infinitos, pero citemos dos como muestra. Durante la batalla de Leuctra entre Tebas y Esparta, Jenofonte narra cómo las armas que se encontraban en el Heracleion desaparecieron, lo que fue interpretado por el ejército tebano como una muestra de que Heracles luchaba con ellos en la batalla. ${ }^{81}$ Que la desaparición de las armas fuera una estratagema de Epaminondas para elevar la moral de su ejército no impide que sus hombres creyeran que Heracles les ayudaba a ellos en vez de a los espartanos, por muy unido que el héroe hubiese estado en el pasado con los lacedemonios.

Pero no siempre eran los dioses olímpicos o los héroes consagrados los que intervenían en los enfrentamientos. Los héroes y dioses locales también eran bienvenidos en las batallas y aunque su adscripción a una polis resulta menos controvertida, ya que muchos apenas si eran conocidos fuera de ella, demuestra la riqueza de la religión que llamamos griega y su falta de homogeneidad como criterio identitario. En esta categoría entraría el caso de Sosípolis, el niño que se convierte en serpiente para ayudar a los eleos en la defensa de su patria contra la invasión de los arcadios y que, según relata Pausanias, ${ }^{82}$ recibió el agradecimiento de los eleos en forma de santuario y establecimiento de culto para él y para su madre.

\section{Conclusión}

De todo lo expuesto podemos concluir, pues, que la religión, efectivamente, funciona como un criterio identitario en el mundo griego, pero en niveles muy diversos. Aquí hemos analizado tres, el panhelénico, el subhelénico y el cívico, pero el estudio podría extenderse a muchas otras categorías que también pueden aportar información interesante, tales como el género, el espacio político, el grupo social, la condición económica... En muchos casos las creencias religiosas, los ritos, los mitos, los dioses, los héroes o los cultos sirven para unir a poblaciones generalmente percibidas como griegas frente a quienes, también generalmente, son tenidos por extranjeros, tal y como como muchas veces se ha defendido. De hecho, los mitos son muy útiles para la construcción de identidades colectivas, puesto que ofrecen solidez y legitimación, pero esto no quiere decir que podamos defender una visión estática de la relación entre el ámbito religioso y el proceso identitario, ya que los cambios sociales son los que organizan, visibilizan, ocultan o modifican los mitos, cultos o ritos, interfiriendo los unos en los otros recíprocamente. ${ }^{83}$

También hemos podido comprobar que lo religioso es a menudo empleado para enfrentar y separar a quienes hasta poco antes y posiblemente algo después de la instrumentalización religiosa concreta que analicemos se consideraban griegos ${ }^{84} \mathrm{e}$ incluso para unir a algunos de ellos con los enemigos de los otros.

\footnotetext{
D. S. 15.53.4; Polyaen. 2.3.8; X. HG. 6.4.7.

Paus. 6.20.3-5.

GeHRKe, 2010; HöLSCHER 2011, 48.

84 De hecho, figuras como Medea, asociada en el imaginario occidental a la Cólquide y, con ella, a una magia oscura ajena a los griegos, es corintia en fuentes arcaicas y mientras que en época arcaica es raro que se incida en los orígenes orientales de Pélope, a partir de mediados del s. V a.C. se hace mucho más frecuente (MiLLER 2011, 69).
} 
El mismo Heródoto, que defiende lo religioso como un elemento de unión entre todos los griegos, dejando aparte otros criterios que ponen en evidencia sus discrepancias, sólo puede, a lo largo de su obra, mencionar como elementos religiosos comunes a los griegos que los diferencian de los persas que estos no tienen estatuas, altares y templos y en los sacrificios no emplean altares, fuego, libaciones, flautas (aunque sí cantos) ni granos de cebada, ${ }^{85}$ lo cual no parece, precisamente, una lista muy definida, sobre todo teniendo en cuenta que Heródoto dice que, aparte de rendir culto al sol, la luna, la tierra, el fuego, el agua y los vientos, los persas también lo hacen a dioses como Urania o Afrodita (a la que llaman Mitra).

La religión debería, pues, perder ese estatus privilegiado como entidad homogénea y renuente al cambio y a la diversidad que le hemos atribuido y analizarse como un factor más, complejo, contradictorio en muchas ocasiones, de los muchos que contribuyen a que una sociedad construya una imagen de sí misma y la reconstruya dependiendo de sus necesidades contextuales.

\section{Referencias bibliográficas}

ALBANIDIS, E. (2004): "The social background of Ancient Olympia victors", [en] E. Albanidis (ed.), Ancient and modern Olympic games: their political and cultural dimensions; $8^{\text {th }}$ International Congress of the European Committee for Sport History, 25-28 September 2003, Ancient Olympia, Greece, Komotini, 43-49.

Allen, K. H. (2003): "Intercultural Exchanges in Fourth-Century Attic Decrees", Classical Antiquity 22/2, 199-250 (http://dx.doi.org/10.1525/ca.2003.22.2.199).

Amandry, P. (1987): “Trépieds de Delphes et du Péloponnèse”, BCH 111/1, 79-131.

Antonaccio, C. (2001): "Ethnicity and colonization", [en] Malkin (ed.), 2001, 113-157.

BaUman, Z. (1996): "From pilgrim to tourist -or a short history of identity", [en] S. Hall - P. Du Guy (eds.), Questions of cultural identity, London, 18-34.

BONNECHERE, P.

(1994): Le sacrifice humain en Grèce ancienne, Liège (http://dx.doi.org/10.400/books. pulg.1031).

(2009): "Le sacrifice humain grec, entre norme e anormalité", [en] P. Brulé (ed.), La norme en matière religieuse en Grèce ancienne, Actes du XIe colloque du CIERGA (Rennes, septiembre 2007), (=Kernos, Supplément 21), Liège, 2009, 189-212 (http://dx.doi. org/10.400/books.pulg.567).

Borza, E. (1990): In the shadow of Olympus: the emergence of Macedon, Princenton.

Bremmer, J. N. (2007): "Myth and ritual in Greek human sacrifice: Lykaon, Polyxena and the case of Rhodian criminal", [en] J. N. Bremmer (ed.), The strange world of human sacrifice, Leuven-Paris-Dudley, 55-79.

BrubaKer, R. (2004): Ethnicity without groups, Cambridge.

Hdt. 1.131-132. En cuanto a los escitas, estos tampoco levantan templos, altares ni estatuas, salvo al dios Ares. Así mismo, Heródoto lista los dioses a los que los escitas rinden culto, y todos los nombres son, como resulta frecuente en el de Halicarnaso, griegos: Hestia, Zeus, Gea, Apolo, Afrodita, Urania, Heracles y Ares (Hdt. 4.59). 
BRÜCK, J. (2007): "Ritual and rationality. Some problems of interpretation in European Archaeology", [en] Insoll (ed.), 2007, 281-307 (http://dx.doi.org/10.1111/j.14679655.2010.01646_2.x).

BURKERT, W.

(1983): Homo Necans: the anthropology of Ancient Greek sacrificial ritual and myth, Los Angeles (http://dx.doi.org/10.151/9783110808476).

(1995): "Greek poleis and civic cults: some further thoughts", [en] M. H. Hansen - K. Raaflaub (eds.), Studies in the Ancient Greek polis, Stuttgart, 201-210.

Butz, P. (1996): "Prohibitionary inscriptions, छÉvor and the influence of the Early Greek polis", [en] R. Hägg (ed.), The role of religion in the Early Greek polis. Proceedings of the Third International Seminar on Ancient Greek cult organized by the Swedish Institute at Athens, 16-18 October 1992, Stockholm, 75-95.

CARDETE, $\mathrm{M}^{\mathrm{a}} \mathrm{C}$.

(2004): "Ethnos y etnicidad en la Grecia clásica", [en] G. Cruz Andreotti - B. Mora Serrano (eds.), Identidades étnicas-identidades políticas en el mundo prerromano hispano, Málaga, 17-29.

(2005a): Paisajes mentales y religiosos de la frontera suroeste arcadia: épocas arcaica y clásica, Oxford.

(2005b): "La polis como articulación social: el caso arcadio", Gerión 23/1, 81-99.

(2006a): "El sacrificio humano: víctimas en el Monte Liceo", Ilu. Revista de Ciencias de las Religiones 11, 93-115.

(2006b): "La etnicidad como arma ideológico-religiosa en la Antigua Grecia: el caso del monte Liceo" SPAL 15, 189-202.

(2007a): "El silencio de los oprimidos: el culto de los Palici", [en] S. Montero - M. C. Cardete (eds.), Religión y silencio. El silencio en las religiones antiguas (='Ilu, Anejo XIX), Madrid, 67-84.

(2007b): "El mito como delimitador de fronteras: Fálaris y las tradiciones cretenses", Polifemo. Rivista di Storia delle Religioni e Storia Antica 7, 193-209.

(2009): "Construcciones identitarias en el mundo antiguo: arqueología y fuentes literarias. El caso de la Sicilia griega", Arqueología Espacial 27, 29-46.

(2010): Paisaje, identidad y religión: imágenes de la Sicilia antigua, Barcelona

(2011): "El valor de la propaganda en la construcción del enemigo: Atenas y las Guerras Médicas", [en] J. M. Cortés - E. Muñiz - R. Gordillo (eds.), Grecia ante los imperios. V Reunión de Historiadores del Mundo Griego Antiguo (=SPAL, Anejo XV), Sevilla, 119130.

(2016): El dios Pan y los paisajes pánicos. De la figura divina al paisaje religioso, Sevilla. (e.p.): "The wrath of gods folds upon men: the case of Ancient Arkadia", [en] Violence in the Ancient and Medieval World, Leuven.

Cartledge, P. (1993): The Greeks, Oxford.

CASERTA, P. (1995): Gli Emmenidi e le tradizioni poetiche e storiografiche su Akragas fino alla battaglia di Himera, Palermo.

CAStriota, D. (2000): "Justice, kingship and imperialism: rhetoric and reality in fifth-century B. C. Representations following the Persian Wars", [en] B. Cohen (ed.), Not the classical ideal. Athens and the construction of the Other in Greek art, Leiden, 443-479.

Christensen, L. B. (2009): “'Cult' in the study of religion and Archaeology”, [en] J. T. Jensen et alii (eds.), Aspects of Ancient Greek cult. Context, ritual, iconography, Aarhus, 13-28.

Christensen, $\mathrm{P}$.

(2007): Olympic victor lists and ancient Greek history, Cambridge (https://doi. org/10.1017/CBO9780511550966). 
(2014): "Sport and democratization in Ancient Greece (with an excursus on athletic nudity)", [en] Christensen - Kyle (eds.), 2014, 211-235 (http://dx.doi.org/10.1002/9781118609965. ch13).

Christensen, P. - Kyle, D. G. (eDs.), (2014): A companion to sport and spectacle in Greek and Roman Antiquity, Chichester (https://dx.doi.org/10.1002/9781118609965).

Crielannd, J. P. (2009): "The Ionians in the Archaic period. Shifting identities in a changing world", [en] Derks - Roymans (eds.), 2009, 37-84.

Dascalakis, A. P. (1983): The Hellenism of the Ancient Macedonians, Amsterdam.

De Polignac, F. (1999-2000): “Offrandes et sanctuaires: contextes, circulations, réseaux et communautés cultuelles”, EPHE 108, 257-260.

De Polignac, F. - Schimtt Pantel, P. (eds.), (2006): L'individu et la communauté. Regards sur les identités en Grèce ancienne. Territoire, organisation de l'espace et cadres sociaux de l'Ionie pré-classique (=REA 108), Bordeaux.

Derks, T. - Roymans, N. (2009): “Introduction”, [en] Derks - Roymans (eds.), 2009, 1-10.

Derks, T. - Roymans, N. (EDS.), (2009): Ethnic constructs in Antiquity: the role of power and tradition, Amsterdam.

Duplouy, A. (2006) : “L’individu et la cité. Quelques stratégies identitaires et leur contexte”, [en] De Polignac - Schimtt Pantel (eds.), 2006, 61-78.

FoRnIs, C. (2008): Grecia exhausta. Ensayo sobre la guerra de Corinto, Göttingen (https:// doi.org/10.13109/9783666252860).

GAllego, J. - VAldÉs Guía, M. (2014): El campesinado ático y el desarrollo de la democracia atenciense, Buenos Aires.

GeHrke, H.-J. (2010): “Greek representations of the past”, [en] L. Foxhall - H.-J. Gehrke N. Luraghi (eds.), Intentional history: spinning time in Ancient Greece, Stuttgart, 15-33.

Georgoud, S. (1974): “Quelques problèmes de la transhumance dans la Grèce ancienne”, REG 87, 155-185.

Golden, M. (1998): Sport and society in Ancient Greece, Cambridge.

Gómez EsPelosín, F.-J. (2004): “La Odisea y la invención del bárbaro 'avant la lettre”,, [en] F. Marco - F. Pina - J. Remesal (eds.), Vivir en tierra extraña: emigración e integración cultural en el mundo antiguo. Actas de la reunión realizada en Zaragoza los días 2 y 3 de junio de 2003, Barcelona, 13-28.

Gruen, E. S. (ED.), (2011): Cultural identity in the Ancient Mediterranean, Los Angeles (https://doi.org/10.1017/S0075426912000377).

HaLl, E. (1989): Inventing the Barbarian. Greek self-definition through tragedy, Oxford.

HALL, J.

(1995): "The role of language in Greek ethnicity", Proceedings of the Cambridge Philological Society 41, 83-100.

(1997): Ethnic identity in Greek antiquity, Cambridge.

(1998): "Discourse and praxis: ethnicity and culture in Ancient Greece", Cambridge Archaeological Journal 8/2, 266-269.

(2001): "Contested ethnicities: perceptions of Macedonia within evolving definitions of Greek Identity”, [en] Malkin (ed.), 2001, 159-186.

(2002): Hellenicity. Between ethnicity and culture, London.

(2003): “Culture' or 'Cultures'? Hellenism in the late sixth century”, [en] C. Dougherty - L. Kurke (eds.), The culture within Ancient Greek culture: contacts, conflicts, collaboration, Cambridge, 23-33. 
Halm-Tisserant, M. (1993): Cannibalisme et immortalité: l'enfant dans le chaudron en Grèce ancienne, Paris.

Hammond, N. G. L. (1989): The Macedonian state: origins, institutions, and history, Oxford.

Haubold, J. (2007): “Xerxes' Homer”, [en] E. Bridges - E. Hall - P. J. Rhodes (eds.), Cultural responses to the Persian wars: Antiquity to the third millennium, Oxford (https://doi. org/10.1093/acprof:oso/9780199279678.001.0001).

HeNRICHS, E. (1981): "Human sacrifices in Greek religion: three cases studies", [en] O. Reverdin - J. Rudhardt (eds.), Le sacrifice dans l'Antiquité. Huit exposés suivis de discussions, Vandoeuvres-Genève 25-30 Août 1980, Vandoeuvres-Genève, 195-235.

HöLSCHER, T. (2011): "Myths, images and the typology of identities in Early Greek art", [en] Gruen (ed.), 2011, 47-65.

Hongman, S. (2007): “Permanence des stratégies culturelles grecques à l'œuvre dans les rencontres inter-ethniques, de l'époque archaïque à l'époque hellénistique", [en] J. M. Luce (éd.), Identités ethniques dans le monde Grec Antique: Actes du Colloque International de Toulouse organisé par le CRATA, 9-11 mars 2006, Toulouse, 125-140.

Hornblower, S. (2008): "Greek identity in the Archaic and Classical Periods", [en] K. Zacharia (ed.), Hellenisms: culture, identity and ethnicity from antiquity to modernity, Aldershot, 37-58 (https://doi.org /10.1111/j.1468-2265.2010.00586_7.x).

Hughes, D. D. (1986): Human sacrifice in Ancient Greece: the literary and archaeological evidence, Ohio.

Insoll, T. (ED.), (2007): The Archaeology of identities, London (http://dx.doi.org/10.1111/ j.1467-9655.2010.01646_2.x).

JACQUEMIN, A. (1999): Offrandes monumentales à Delphes, Paris.

Jones, S. - Graves-Brown, P. (1996): "Introduction. Archaeology and cultural identity in Europe", [en] P. Graves-Brown - C. Gamble - S. Jones (eds.), Cultural identity and Archaeology: the construction of European communities, London, 1-24.

Jost, M.

(2002): “À propos des sacrifices humains dans le sanctuaire de Zeus du mont Lycée”, [en] R. Hägg (ed.), Peloponnesian sanctuaries and cults. Proceedings of the ninth International Seminar on Ancient Greek cult organized by the Swedish Institute at Athens, 11-13 June 1994, Stockholm, 183-186.

(2005): "Deux mythes de métamorphose en animal et leurs interprétation: Lykaon et Ka1listo", Kernos 18, 347-470 (http://dx.doi.org/10.4000/kernos.1909).

Konstan, D. (2001): "To Hellenikon ethnos: ethnicity and the construction of Ancient Greek identity", [en] Malkin (ed.), 2001, 29-50.

KYLE, D. G.

(2007): Sport and spectacle in the ancient world, Malden-Oxford (http://dx.doi. org/10.1111/j.1540-6563.2008.00233_53.x).

(2014): "Greek females sport: rites, running and racing", [en] Christensen - Kyle (eds.), 2014, 258-275 (http://dx.doi.org/10.1002/9781118609965.ch16).

LANE Fox, R. (ED.), (2011): Brill's companion to ancient Macedon: studies in the archaeology and history of Macedon, $650 \mathrm{BC}-300 \mathrm{AD}$, Leiden.

LÉVY, E.

(1984): "Naissance du concept de barbare", Ktema 9, 5-14.

(1991): “Apparition des notions de Grèce et de grecs”, [en] Saïd (ed.), 1991, 49-69.

Lucy, S. (2005): "Ethnic and cultural identities”, [en] M. Díaz-Andreu - S. Lucy - S. Babić D. N. Edwards, The Archaeology of identity. Approaches to gender, age, status, ethnicity and religion, London-New York, 86-109. 
MaLKIN, I. (ED.), (2001): Ancient perceptions of Greek ethnicity, Washington.

Mann, C. H. (2014): "People on the fringes of Greek sport", [en] Christensen - Kyle (eds.), 2014, 276-286 (http://dx.doi.org/10.1002/9781118609965.ch17).

Meskell, L. (2007): “Archaeologies of identity”, [en] Insoll (ed.), 2007, 23-43 (http://dx.doi. org 10.1111/j.1467-9655.2010.01646_2.x).

Miller, M. C. (2011): "Barbarian lineage in classical Greek mythology and art: Pelops, Danaos and Kadmos", [en] Gruen (ed.), 2011, 68-89.

MiLler, S. G. (2004): Ancient Greek athletics, New Haven-London.

MogGi, $\mathrm{M}$.

(1991): “Greci e barbari: uomini e no", [en] L. De Finis (ed.), Civiltà classica e mondo dei barbari: due modelli a confronto, Trento, 31-46.

(1992): "Straniero due volte: il barbaro e il mondo greco", [en] M. Bettini (ed.), Lo straniero: ovvero l'identità culturale a confronto, Roma, 51-76.

MoretTi, L. (1957): Olympionikai. I vincitori negli antichi agoni olimpici, Roma.

Morgan, C.

(1990): Athletes and oracles: the transformation of Olympia and Delphi in the eight century $B C$, Cambridge.

(2007): "Sport and the construction of socio-political identity in Archaic and Classical Greece", [en] B. Kratzmüller et alii (eds.), Sport and the construction of identities. Proceedings of the XIth International CESH-Congress, Vienna, September $17^{\text {th }}-20^{\text {th }}$ 2006, Wien, 117-129.

NichOLSON, N. J.

(2005): Aristocracy and athletics in Archaic and Classical Greece, Cambridge. (2014): "Representations of sport in Greek Literature", [en] Christensen - Kyle (eds.), 2014, 68-80 (http://dx.doi.org/10.1002/9781118609965.ch4).

NiELS, J. (2014): "Picturing victory: representations of sport in Greek art", [en] Christensen Kyle (eds.), 2014, 81-97 (http://dx.doi.org/10.1002/9781118609965.ch5).

NiELSEN, T. H.

(1999): "The concept of Arkadia- the people, their land and their organisation", [en] T. H. Nielsen - J. Roy (eds.), Defining Ancient Arkadia. Acts of the Copenhagen Polis Centre, Copenhagen, vol. 6, 16-88.

(2002): Arkadia and its poleis in the Archaic and Classical Periods, Göttingen. (2007): Olympia and the Classical Hellenic state city-culture, Copenhagen. (2014): "Panhellenic athletics at Olympia", [en] Christensen - Kyle (eds.), 2014, 133-145 (http://dx.doi.org/10.1002/9781118609965.ch8).

Osborne, R. (2012): "Landscape, ethnicity and the polis", [en] G. Cifani - S. Stoddart (eds.), Landscape, ethnicity and identity in the pre-Roman Mediterranean, Oxford, 24-31.

Pleket, H. W. (2014): "Inscriptions as evidence of Greek sport", [en] Christensen - Kyle (eds.), 2014, 98-111 (http://dx.doi.org/10.1002/9781118609965.ch6).

Roisman, J. - Worthington, I. (EDS.), (2010): A companion to ancient Macedonia, Oxford (http://dx.doi.org/10.1002/9781444327519.ch5)

Romano, D. G. - Voyatzis, M. (2010): "Preserving Ancient Arcadia Heritage: proposal for an archaeological park", [en] P. Carlier - Ch. Lerouge-Cohen (eds.), Paysage et religion en Grèce antique. Mélanges offerts à Madeleine Jost, Paris, 41-54.

Roy, J. (2009): "Living in the mountains: Arkadian identity in the Classical Period", [en] M. Georgiadis - Ch. Gallou (eds.), The past in the past: the significance of memory and tradition in the transmission of culture, Oxford, 57-65. 
SAÏD, S. (2001): "The discourse of identity in Greek rhetoric from Isocrates to Aristides", [en] Malkin (ed.), 2001, 275-299.

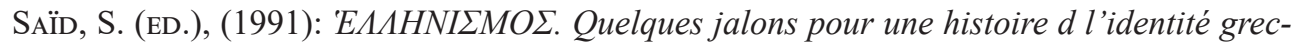
que. Actes du Colloque de Strasbourg 25-27 octobre 1989, Leiden.

Santiago, R. A. (1998): “Griegos y bárbaros: arqueología de una alteridad”, Faventia 20/2, $33-45$.

Sebillotte Cuchet, V. (2006): “Affective et politique: la question de l'attachement individuel à la cité”, [en] De Polignac - Schimtt Pantel (eds.), 2006, 115-132.

SHEEDY, K. (2007): Alexander and the Hellenistic kingdoms: coins, image and the creation of identity: the Westmoreland collection, Sydney.

SinN, U. (2014): "Olympia: the place of contests in the cult of Zeus Olympios", [en] T. F. Scanlon (ed.), Sport in the Greek and Roman worlds. Vol. 1, Early Greece, the Olympics, and contests, Oxford, 120-142.

Sorensen, M. L. S. (2013): "Introduction to Part I: belief as practice, [en] M. L. S. Sorensen - K. Rebay-Salisbury (eds.), Embodied knowledge: perspectives on belief and technology, Oxford, 2013, 11-14.

SwIFT, L. (2008): Euripides: Ion, London.

Tracy, S. V. (2003): Athens and Macedon: Attic letter-cutters of 300 to 229 B.C., Berkeley (http://dx.doi.org/10.1525/california/9780520233331.001.0001).

TrÉDÉ, M. (1991): “Quelques définitions de l'hellénisme au IVe siècle avant J.-C. et leurs implications politiques”, [en] Saïd (ed.), 1991, 71-80.

VALDÉS, M.

(2006): “Apolo Patroos, el ancestro de los atenienses y las tribus jónicas”, [en] D. Plácido et alii (eds.), La construcción ideológica de la ciudadanía. Identidades culturales y sociedad en el mundo griego antiguo, Madrid, 129-146.

(2015): "De las Calqueas a las Hefestias: consideraciones sobre los artesanos, la ciudadanía y Hefesto", Dialogues d'Histoire Ancienne 41/2, 19-40 (http://dx.doi.org/10.3917/ dha.412.0019).

VEYNE, P. (1987): ¿Creyeron los griegos en sus mitos?: ensayo sobre la imaginación constituyente, Buenos Aires.

ZaCharia, K. (2003): Converting Truths. Euripides' Ion and the Athenian quest for selfdefinition, Leiden-Boston.

ZeitLIn, F. I. (1989): “Mysteries of identity and designs of the self in Euripides' Ion”, The Cambridge Classical Journal 35, 144-197 (http://dx.doi.org/10.1017/S0068673500005174). 